\title{
Review \\ Effect of pistachio on plasma lipids concentration: a meta-analysis of randomized controlled trials
}

\author{
[Efecto del pistacho sobre la concentración de lípidos plasmáticos: \\ un metanálisis de ensayos controlados aleatorios] \\ Mahbubeh Bozorgi ${ }^{1}$, Shekoufeh Nikfar ${ }^{2,3}$, Mohammad Abdollahi ${ }^{4,5}$ \& Roja Rahimi ${ }^{1,3 *}$ \\ ${ }^{1}$ Department of Traditional Pharmacy, School of Persian Medicine, Tehran University of Medical Sciences, Tehran, Iran \\ ${ }^{2}$ Department of Pharmacoeconomics and Pharmaceutical Administration, Faculty of Pharmacy, \\ Tehran University of Medical Sciences, Tehran, Iran \\ ${ }^{3}$ Evidence-Based Medicine Group, Pharmaceutical Sciences Research Center, Tehran University of Medical Sciences, Tehran, Iran \\ ${ }^{4}$ Toxicology and Diseases Group, Pharmaceutical Sciences Research Center, Tehran University of Medical Sciences, Tehran, Iran; \\ ${ }^{5}$ Department of Toxicology and Pharmacology, Faculty of Pharmacy, Tehran University of Medical Sciences, Tehran, Iran \\ *Correspondence to: rojarahimi@gmail.com
}

\begin{abstract}
Dyslipidemia and lipoprotein metabolism disorder are involved in pathogenesis of many important diseases such as diabetes, atherosclerosis, acute pancreatitis, and malignancies. The present study aimed to evaluate the effect of pistachio on plasma lipids. Electronic databases including Scopus, Pubmed, Science Direct, and Cochrane library were searched with the keywords "lipoprotein", "blood lipid", "dyslipidemia" or "hyperlipidemia" with "Pistachio" until June 2019. Two review authors independently checked eligibility and extracted data using a standard form. Information extracted included characteristics of the patients, dose of treatment, trial duration, quality score, and trial outcomes. Four randomized clinical trials with 213 subjects worked on the effect of pistachio on blood lipids were included. Comparison of pistachio rich diet with control yielded a significant effect size of -2.6 (95\% CI: $-4.4--0.7, p=0.006)$ for mean reduction in total cholesterol, a significant effect size of 5.1 (95\% CI: $1.8-8.3, p=0.002)$ for mean increase in HDL-cholesterol, a non-significant effect size of -0.3 (95\% CI: $-0.8-0.3, p=0.4)$ for mean reduction in LDL-cholesterol and a non-significant effect size of $-1.3(95 \%$ CI: $-4.4-1.7, p=0.4)$ for mean reduction in triglyceride from baseline. The results demonstrated significant effect of pistachio on reducing total cholesterol and increasing HDLcholesterol; however, its effect on lowering LDL-cholesterol and triglyceride was not significant. Further clinical trials are needed to confirm whether pistachio consumption for a certain period of time can significantly influence blood lipids.
\end{abstract}

Keywords: Pistachio; Lipoprotein; Hyperlipidemia; Hypercholesterolemia; Hypertriglyceridemia, Meta-analysis

Resumen: La dislipidemia y el trastorno del metabolismo de las lipoproteínas están implicados en la patogénesis de muchas enfermedades importantes como la diabetes, la aterosclerosis, la pancreatitis aguda y las neoplasias malignas. El presente estudio tuvo como objetivo evaluar el efecto del pistacho sobre los lípidos plasmáticos. Se realizaron búsquedas en bases de datos electrónicas, incluidas Scopus, Pubmed, Science Direct y Cochrane Library, con las palabras clave "lipoprotein", "blood lipid", "dislipidemia" o "hyperlipidemia" con "Pistachio" hasta junio de 2019. Dos autores de la revisión verificaron de forma independiente la elegibilidad y extrajeron datos utilizando un formulario estándar. La información extraída incluyó características de los pacientes, dosis de tratamiento, duración del ensayo, puntuación de calidad y resultados del ensayo. Se incluyeron cuatro ensayos clínicos aleatorios con 213 sujetos que trabajaron sobre el efecto del pistacho en los lípidos en sangre. La comparación de la dieta rica en pistacho con el control arrojó un tamaño del efecto significativo de -2,6 (IC del 95\%: -4,4 - -0,7, p=0,006) para la reducción media del colesterol total, un tamaño del efecto significativo de 5,1 (IC del 95\%: 1,8 $8,3, p=0,002$ ) para el aumento medio del colesterol HDL, un tamaño del efecto no significativo de $-0,3$ (IC del 95\%: $-0,8-0,3, p=0,4$ ) para la reducción media del colesterol LDL y un efecto no significativo tamaño de -1,3 (IC del 95\%: -4,4 - 1,7, $p=0,4$ ) para la reducción media de los triglicéridos desde el valor inicial. Los resultados demostraron un efecto significativo del pistacho en la reducción del colesterol total y el aumento del colesterol HDL; sin embargo, su efecto sobre la reducción del colesterol LDL y los triglicéridos no fue significativo. Se necesitan más ensayos clínicos para confirmar si el consumo de pistacho durante un cierto período de tiempo puede influir significativamente en los lípidos en sangre.

Palabras clave: Pistacho; Lipoproteína; Hiperlipidemia; Hipercolesterolemia; Hipertrigliceridemia, metanálisis

Received: March 27, 2021

Accepted: May, 15, 2021

Published online: May 30, 2021

This article must be cited as: Bozorgi M, Nikfar S, Abdollahi M, Rahimi R. 2021. Effect of pistachio on plasma lipids concentration: a meta-analysis of randomized controlled trials. Med Plant Commun 4 (1): 1 - 13. 


\section{ABBREVIATIONS}

CVD: cardiovascular diseases; HDL-C: HDL cholesterol; LDL-C: low-density lipoprotein cholesterol; non-HDL-C: non-high-density lipoprotein cholesterol; TC: total cholesterol; TG: triglyceride

\section{INTRODUCTION}

Dyslipidemia and lipoprotein metabolism disorders with various etiology, is defined as increase in total cholesterol (TC), low-density lipoprotein cholesterol (LDL-C), non-high-density lipoprotein cholesterol (non-HDL-C), triglyceride or some combination of them in addition to reduction of HDL cholesterol (HDL-C) (Expert Panel on Detection, 2001). Dyslipidemia is involved in pathogenesis of diabetes, atherosclerosis, acute pancreatitis, nephropathy, breast cancer, and other malignancies (Koene et al., 2016). Moreover, dyslipidemia is an important risk factor for cardiovascular diseases (CVD), one of the main causes of death worldwide (Yusuf et al., 2004). Death rates among people with CVD are rising and the number of people who will die from CVD in 2030 is estimated nearly 23.6 million (Mathers \& Loncar, 2006). Management of dyslipidemia, as a preventive strategy for cardiovascular disease, may result in reduction of cardiovascular morbidity and mortality (Pan et al., 2016). Sometimes, conventional medicines have been successful in treating dyslipidemia but the success has been limited with some adverse effects like myopathy, rhabdomyolysis, and hepatic enzyme abnormalities (Gotto \& Toth, 2016).

Via different human and animal studies, it was established that consumption of naturally derived supplements can be effective in controlling dyslipidemia. So nutritional supplements beside the other lifestyle modifications such as exercise and smoking cessation is recommended as the first intervention for treating dyslipidemia (Gotto \& Toth, 2016; Bahramsoltani et al., 2017).

Pistachio (Pistacia vera L.) from the family Anacardiaceae is one of the oldest flowering nut trees considered as part of human food since 7000 BC (DerMarderosian \& Beutler, 2002). Pistachio is native to the Middle East and ancient Mediterranean civilization used seeds, nut shell, oil and resin of the plant for various therapeutic purposes (Dreher, 2012; Bozorgi et al., 2013). Iran, USA and Turkey are the main producers of Pistachio with a slight difference in nutritional constituents (Bulló et al., 2015). Pistachio contains mono and polyunsaturated fatty acids, protein and dietary fiber. In addition, this nut is a rich source of phytosterols, carotenoids, $\gamma$-tocopherol, vitamin $\mathrm{K}$, phenolic compounds and certain minerals like potassium, magnesium and Iron (Dreher, 2012; Bozorgi et al., 2013). Important records via in vitro and in vivo studies showed that pistachio has remarkable antioxidant, anti-inflammatory, anti-tumor and antiatherosclerosis and antimicrobial properties (Bozorgi et al., 2013).

Some clinical trials have reported the impact of pistachio on control of body-weight and blood pressure, insulin resistance and diabetes (Bulló et al., 2015). In addition, several clinical trials have determined the effect of pistachio supplements on plasma lipid markers but the results were inconsistence. Although a meta-analysis assessing the effect of nuts on lipids has been published (Del Gobbo et al., 2015), to the best of our knowledge, no attempt was made to meta-analyze the data of pistachio as an individual intervention. Therefore, present meta-analysis was conducted to determine the efficacy of pistachio in plasma lipid profile using data from available clinical trials to determine its role as a lipid modulator.

\section{METHODS}

\section{Data sources and searches}

A literature search was conducted on the electronic databases of Scopus, PubMed, Science Direct, and Cochrane Central Register of Controlled Trials. The search was carried out without time restriction from 1966 to June 2019 using following search strings in the title/abstract/keywords: "Pistachio AND Dyslipidemia, Pistachio AND Dyslipoproteinemia, Pistachio AND Lipoprotein, Pistachio AND blood lipids". All the relevant papers were included, irrespective of when and where they were conducted. The reference lists from earlier published review articles and the retrieved papers were manually reviewed for additional applicable studies. The initial search results were recorded for investigating whether they can be included in meta-analysis. An initial assessment was performed by two authors independently, based on the title and abstract of each article to examine the potential of inclusion in the meta-analysis. The duplicate articles and irrelevant papers were excluded. The review articles and the non-human (in vitro and animal) studies were also excluded. Included articles were randomized controlled clinical trials examining the effect of pistachio on serum lipid profile. Regarding these articles, the authors individually extracted and categorized data on the 
characteristics of the patients, dose of treatment, trial duration, quality score, and trial outcomes. Figure 1 illustrates a diagram of the study selection process.

\section{Quality assessment}

To determine the quality of included studies, Jadad score was used that rates the studies in terms of description of randomization, blinding, and dropouts (withdrawals) (Jadad, 1998). The quality scale ranges from 0 to 5 from low to high. A quality score of at least 3 was considered eligible to include.

\section{Statistical analysis}

According to meta-analysis general rule, included studies were weighted by effect size, pooled and analyzed using Statsdirect software version 3.1.14. Standardized effect size and $95 \%$ confidence intervals $(95 \% \mathrm{CI})$ were calculated using Der Simonian-Laird (for random effects) method. The Cochran Q test was used to test heterogeneity and $\mathrm{p}<0.05$ considered significant. In case of acceptable heterogeneity or few included studies, the random effects model was used. Egger and Begg-Mazumdar tests were used to evaluate publication bias indicators in funnel plot.

\section{RESULTS}

The electronic search yielded 129 items; 20 from PubMed, 75 from Scopus, 12 from Science Direct and 22 from the Cochrane Library. Of these, 9 trials were scrutinized in full text. Five reports were considered ineligible: two investigated the effects of pistachio in diabetic and pre-diabetic patients (Hernández-Alonso et al., 2014; Sauder et al., 2015) and three invested different types of diet in addition to pistachio (Sheridan et al., 2007; Gebauer et al., 2008; Li et al., 2010). Thus, 4 trials were included in the analysis representing 213 subjects (Figure No. 1). All of the included studies obtained Jadad score of 3 or more (Table No. 1). Among the studies included, 2 assessed the effect of pistachio on blood lipids in patients with metabolic syndrome (Wang et al., 2012; Gulati et al., 2014) and two other studies included patients with dyslipidemia or healthy volunteers (Kocyigit et al., 2006; Kasliwal et al., 2015).

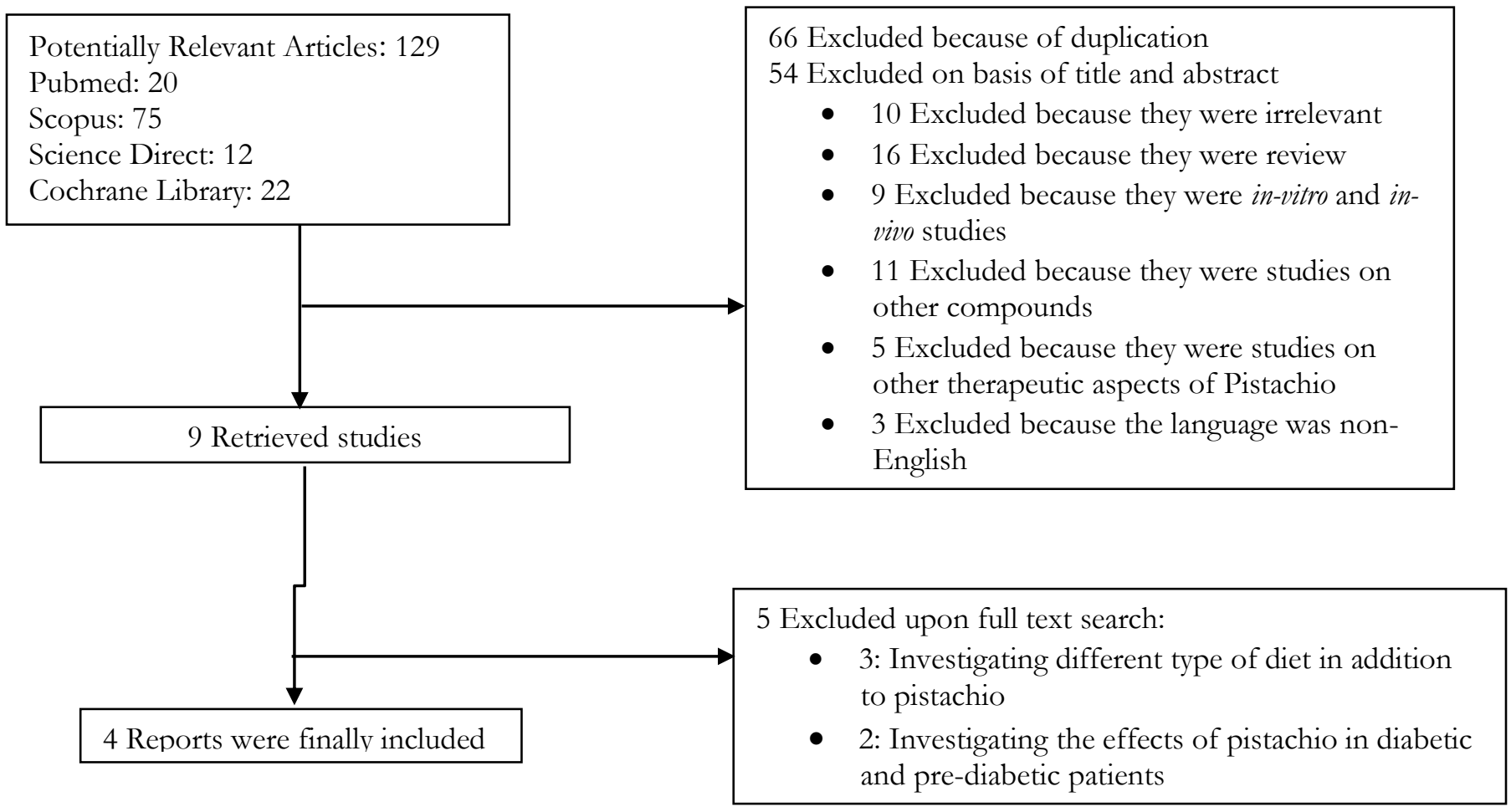

Figure No. 1

Flow diagram for study selection

Medicinal Plant Communications / 3 
Table No. 1

Characteristics of studies investigating the efficacy of pistachio in lowering plasma lipids

\begin{tabular}{|c|c|c|c|c|c|c|c|c|c|}
\hline \multirow[t]{3}{*}{ Study } & \multirow[t]{3}{*}{ Dose } & \multicolumn{5}{|c|}{ Population } & \multirow[t]{3}{*}{ Duration } & \multirow{3}{*}{$\begin{array}{c}\text { Investigated } \\
\text { outcomes }\end{array}$} & \multirow{3}{*}{$\begin{array}{l}\text { Jaded } \\
\text { score }\end{array}$} \\
\hline & & \multirow{2}{*}{ Type } & \multicolumn{2}{|c|}{$\mathbf{M} / \mathbf{F}$} & \multicolumn{2}{|c|}{ Mean age } & & & \\
\hline & & & Pistachio & Placebo & Pistachio & Placebo & & & \\
\hline $\begin{array}{c}\text { Kasliwal } \\
\text { et al., } \\
2015\end{array}$ & 40g/day & $\begin{array}{l}\text { Patients with } \\
\text { dyslipidemia }\end{array}$ & $26 / 3$ & $20 / 7$ & $37.7 \pm 7.6$ & $40.4 \pm 8.2$ & $\begin{array}{c}3 \\
\text { monthes }\end{array}$ & $\begin{array}{c}\text { Body mass index, } \\
\text { Systolic BP, } \\
\text { Diastolic BP, } \\
\text { Fasting blood } \\
\text { sugar, hs-CRP, } \\
\text { Total cholesterol, } \\
\text { Serum } \\
\text { triacylglycerols, } \\
\text { HDL cholesterol, } \\
\text { LDL cholesterol, } \\
\text { Apo-A1, Apo-B, } \\
\text { Total/HDL-C } \\
\text { ratio, Apo- } \\
\text { A1/Apo-B ratio }\end{array}$ & 3 \\
\hline $\begin{array}{l}\text { Gulati } \\
\text { et al., } \\
2014\end{array}$ & 49 g/day & $\begin{array}{l}\text { Metabolic } \\
\text { syndrome }\end{array}$ & $23 / 10$ & $14 / 21$ & $41.6 \pm 8.4$ & $43.3 \pm 8.1$ & 24 weeks & $\begin{array}{l}\text { fasting blood } \\
\text { glucose, free fatty } \\
\text { acid; HDL-C, } \\
\text { high-density } \\
\text { lipoprotein } \\
\text { cholesterol; hs- } \\
\text { CRP, high- } \\
\text { sensitivity C- } \\
\text { reactive protein; } \\
\text { IAAT, } \\
\text { intraabdominal } \\
\text { adipose tissue; } \\
\text { LDL-C, low- } \\
\text { density } \\
\text { lipoprotein } \\
\text { cholesterol; } \\
\text { SCAT, } \\
\text { subcutaneous } \\
\text { abdominal } \\
\text { adipose tissue; } \\
\text { TBARS, } \\
\text { thiobarbituric acid } \\
\text { reactive } \\
\text { substances; TG, } \\
\text { triglyceride; TNF, } \\
\text { tumor necrosis } \\
\text { factor; WC, waist } \\
\text { circumference }\end{array}$ & 2 \\
\hline $\begin{array}{l}\text { Kocyigit } \\
\text { et al., } \\
2006\end{array}$ & $\begin{array}{c}65 \text { to } 75 \\
\text { g/day }\end{array}$ & $\begin{array}{c}\text { healthy } \\
\text { volunteers }\end{array}$ & $12 / 10$ & $12 / 10$ & $\begin{array}{c}33.4 \pm 7.2 \\
\text { years }\end{array}$ & $32.8 \pm 6.7$ & 3 weeks & $\begin{array}{l}\text { total cholesterol, } \\
\text { low-density } \\
\text { lipoprotein } \\
\text { (LDL), high- } \\
\text { density } \\
\text { lipoprotein } \\
\text { (HDL), } \\
\text { triglyceride, } \\
\text { malondialdehyde } \\
\text { (MDA) and }\end{array}$ & 2 \\
\hline
\end{tabular}




\begin{tabular}{|c|c|c|c|c|c|c|c|c|c|}
\hline & & & & & & & & $\begin{array}{c}\text { antioxidant } \\
\text { potential (AOP) }\end{array}$ & \\
\hline $\begin{array}{l}\text { Wang } \\
\text { et al., } \\
2012\end{array}$ & 70 g/day & $\begin{array}{l}\text { metabolic } \\
\text { syndrome }\end{array}$ & $12 / 18$ & $13 / 17$ & $\begin{array}{l}51.89 \pm 8.82 \\
51.83 \pm 9.37\end{array}$ & $50.66 \pm 9.86$ & 12 weeks & $\begin{array}{c}\text { BMI, Fasting } \\
\text { Glucose } \\
\text { (mmol/L), Fasting } \\
\text { Insulin (mU/L), } \\
\text { Total cholesterol } \\
\text { (mmol/L), } \\
\text { Triglyceride } \\
\text { (mmol/L), } \\
\text { LDL }(\mathrm{mmol} / \mathrm{L}), \\
\text { HDL }(\mathrm{mmol} / \mathrm{L})\end{array}$ & 3 \\
\hline
\end{tabular}

Effect of pistachio compared to placebo on total cholesterol (TC) in patients with metabolic syndrome and healthy people

The summary for standardized effect size on mean differences on total cholesterol (TC) " $\Delta \mathrm{TC}$ " in patients with metabolic syndrome and healthy people from 4 trials for pistachio therapy (Kocyigit et al., 2006; Wang et al., 2012; Gulati et al., 2014; Kasliwal et al., 2015) compared to placebo was -2.6 with $95 \%$ CI $=-4.4$ to -0.7 ( $p=0.006$, Figure No. 2). The Cochrane Q test for heterogeneity indicated that the studies are heterogeneous $(p<0.0001)$ and could not be combined and also publication bias, the random effects for individual and summary of effect size for standardized mean was applied. For evaluation of publication bias Egger regression of normalized effect vs. precision for all included studies for " $\Delta \mathrm{TC}$ " in patients with metabolic syndrome and healthy people among pistachio vs. placebo therapy was $10.12(95 \% \mathrm{CI}=-18.06$ to $-2.18, p=0.03)$ and Begg-Mazumdar Kendall's test on the standardized effect vs. variance indicated tau $=-0.33, p=0.38$ (Figure No. 3).

\section{Effect size meta-analysis plot [fixed effects]}

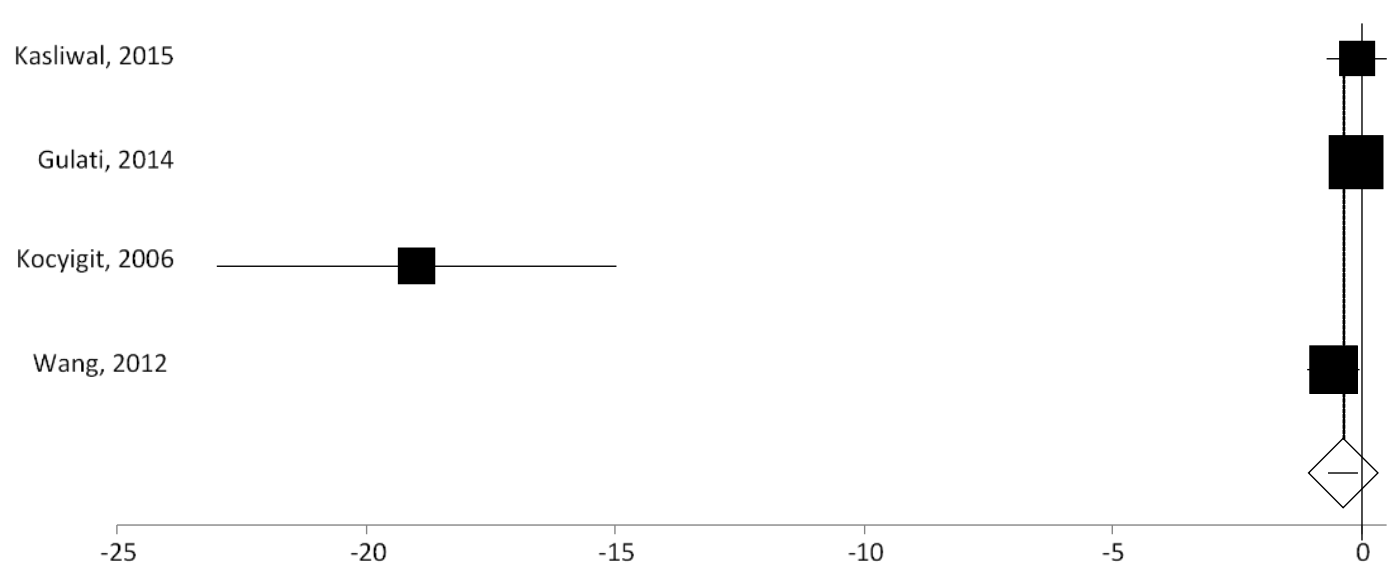

pooled effect size $=-0.4(95 \% \mathrm{Cl}=-0.7$ to -0.07$)$

Figure No. 2

Individual and pooled effect size for the outcome of " $\Delta \mathrm{TC}$ " in the studies considering pistachio comparing to placebo therapy in metabolic syndrome patients and healthy people

Effect of pistachio compared to placebo in total LDL in patients with metabolic syndrome and healthy people The summary for standardized effect size on mean differences of LDL " $\Delta$ LDL" in patients with metabolic syndrome and healthy people from 4 trials for pistachio therapy (Kocyigit et al., 2006; Wang et al., 2012; Gulati et al., 2014; Kasliwal et al., 2015) compared to placebo was -0.3 with $95 \% \mathrm{CI}=-0.8$ to 0.3 ( $p=0.4$, Figure No. 4). The Cochrane Q test for heterogeneity indicated that the studies are heterogeneous $(p=0.005)$ and could not be combined, thus the random effects for individual and summary of effect size for standardized mean was applied. For evaluation of publication bias Egger regression of normalized effect vs. precision for all included studies for " $\Delta$ LDL" in patients with metabolic 
syndrome and healthy people among pistachio vs. placebo therapy was -9.5 ( $95 \% \mathrm{CI}=-46.3$ to $27.3, p=0.38)$ and $\mathrm{Begg}$ Mazumdar Kendall's test on the standardized effect vs. variance indicated tau $=-0.67, p=0.08$ (Figure No. 5).

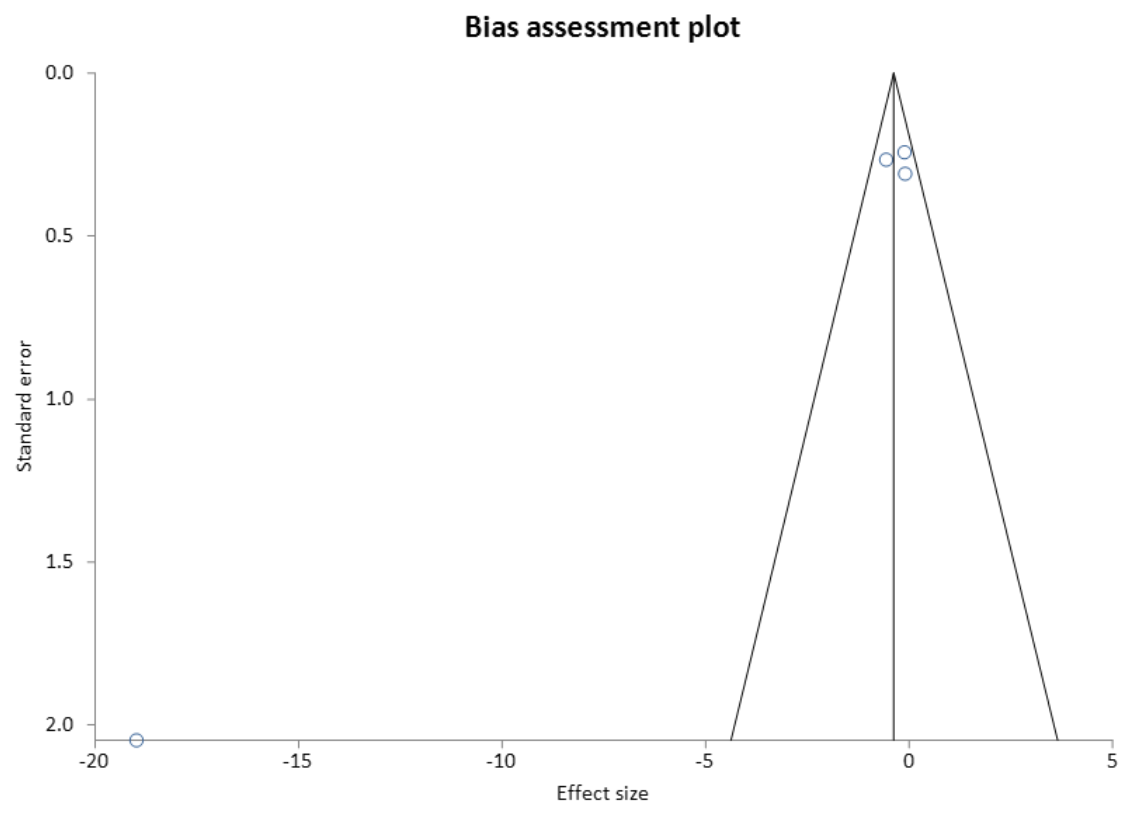

Figure No. 3

Publication bias indicators for the outcome of " $\Delta \mathrm{TC}$ " in the studies considering pistachio comparing to placebo therapy in metabolic syndrome patients and healthy people

\section{Effect size meta-analysis plot [random effects]}

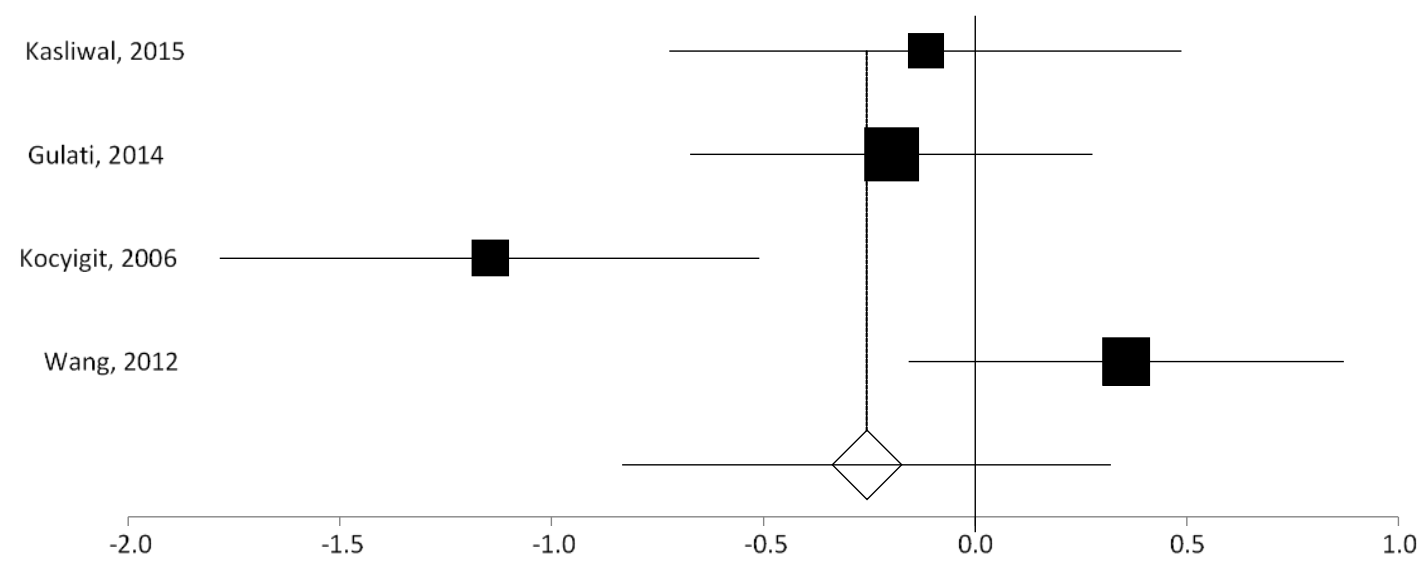

DL pooled effect size $=-0.3(95 \% \mathrm{Cl}=-0.8$ to 0.3$)$

Figure No. 4

Individual and pooled effect size for the outcome of " $\triangle L D L$ " in the studies considering pistachio comparing to placebo therapy in metabolic syndrome patients and healthy people 


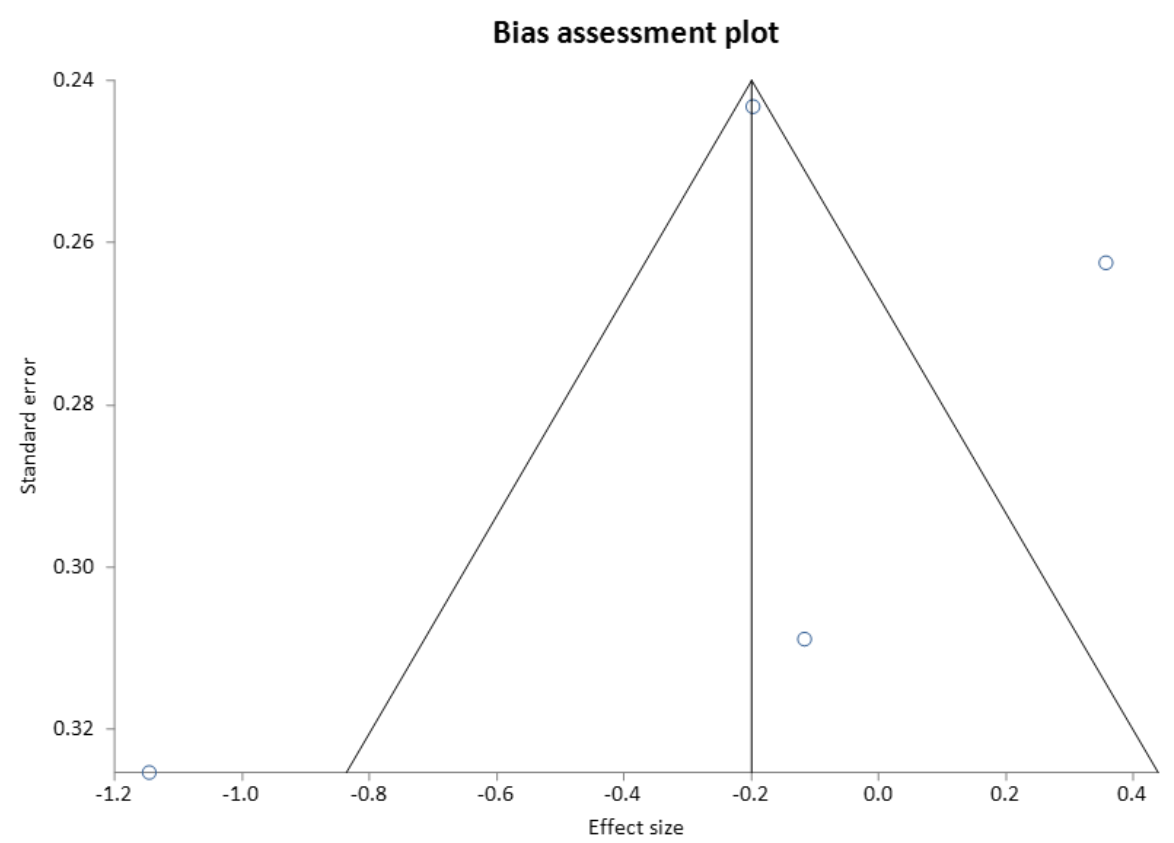

Figure No. 5

Publication bias indicators for the outcome of " $\Delta \mathbf{L D L}$ " in the studies considering pistachio comparing to placebo therapy in metabolic syndrome patients and healthy people

Effect of pistachio compared to placebo on total HDL in patients with metabolic syndrome and healthy people

The summary for standardized effect size on mean differences of HDL " $\Delta H D L$ " in patients with metabolic syndrome and healthy people from 3 trials for pistachio therapy compared to placebo (Kocyigit et al., 2006; Gulati et al., 2014; Kasliwal et al., 2015;) was 5.1 with $95 \%$ CI= 1.8 to 8.3 ( $p=0.002$, Figure No. 6). The Cochrane Q test for heterogeneity indicated that the studies are heterogeneous $(p<0.0001)$ and could not be combined, thus the random effects for individual and summary of effect size for standardized mean was applied. For evaluation of publication bias Egger regression of normalized effect vs. precision for all included studies for " $\Delta H D L$ " in patients with metabolic syndrome and healthy people among pistachio vs. placebo therapy could not be calculated because of too few strata.

Effect size meta-analysis plot [random effects]

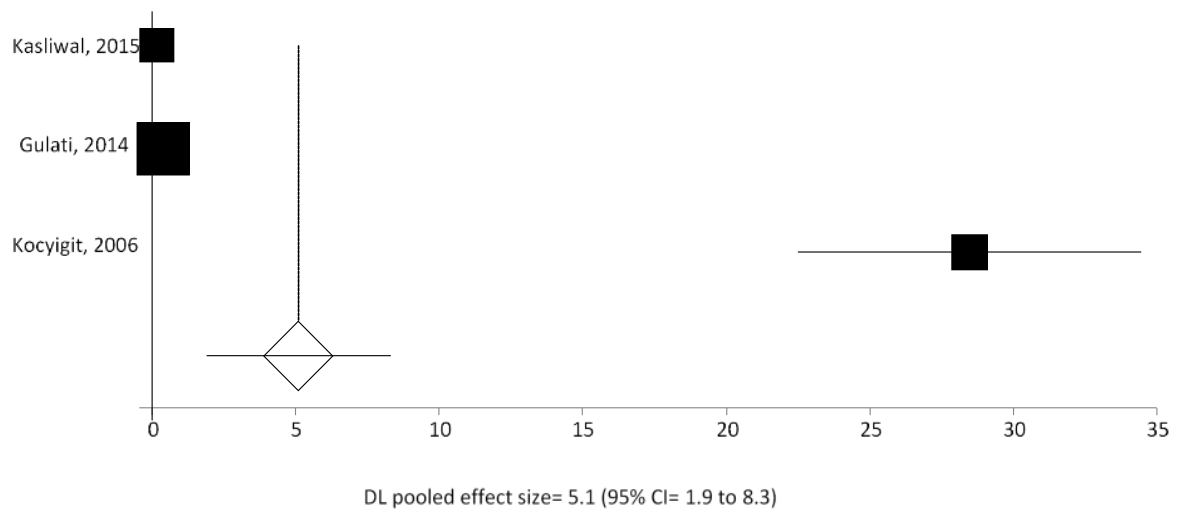

Figure No. 6

Individual and pooled effect size for the outcome of " $\triangle \mathrm{HDL}$ " in the studies considering pistachio comparing to placebo therapy in metabolic syndrome patients and healthy people 
Effect of pistachio compared to placebo $\mathrm{n}$ total TG in patients with metabolic syndrome and healthy people The summary for standardized effect size on mean differences of TG " $\Delta T G$ " in patients with metabolic syndrome and healthy people from 4 trials for pistachio therapy compared to placebo (Kocyigit et al., 2006; Wang et al., 2012; Gulati et al., 2014; Kasliwal et al., 2015) was -1.3 with 95\% CI= -4.4 to 1.7 ( $p=0.4$, Figure No. 7). The Cochrane Q test for heterogeneity indicated that the studies are heterogeneous $(p<0.0001)$ and could not be combined, thus the random effects for individual and summary of effect size for standardized mean was applied. For evaluation of publication bias Egger regression of normalized effect vs. precision for all included studies for " $\Delta \mathrm{TG}$ " in patients with metabolic syndrome and healthy people among pistachio vs. placebo therapy was $-2.8(95 \% \mathrm{CI}=-46.3$ to $40.7, p=0.81)$ and BeggMazumdar Kendall's test on the standardized effect vs. variance indicated tau $=0, p=0.75$ (Figure No. 8).

Effect size meta-analysis plot [random effects]

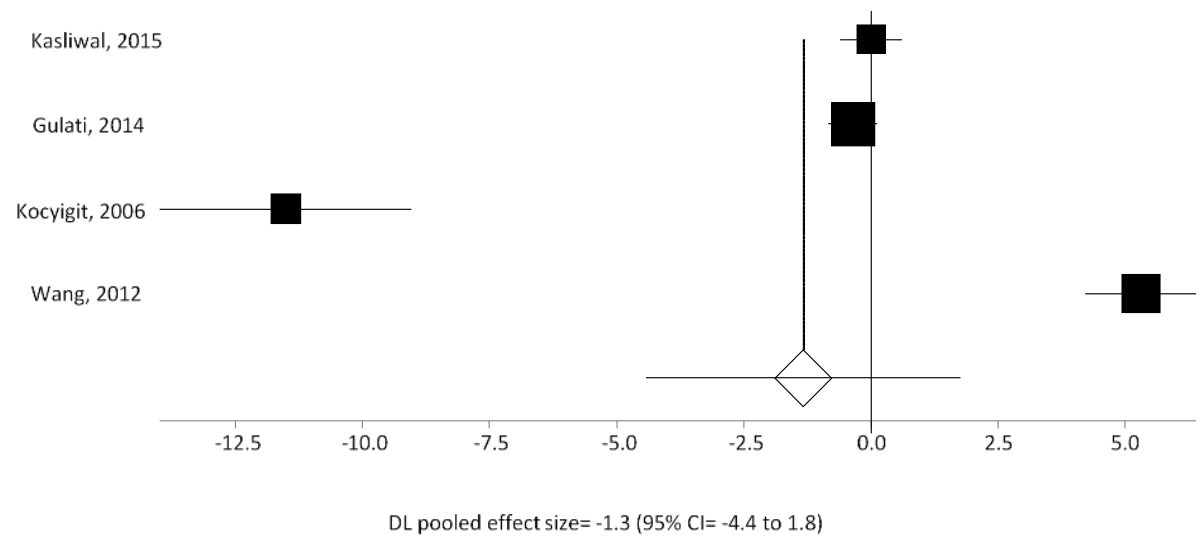

Figure No. 7

Individual and pooled effect size for the outcome of " $\Delta \mathrm{TG"} \mathrm{in} \mathrm{the} \mathrm{studies} \mathrm{considering} \mathrm{pistachio} \mathrm{comparing} \mathrm{to}$ placebo therapy in metabolic syndrome patients and healthy people

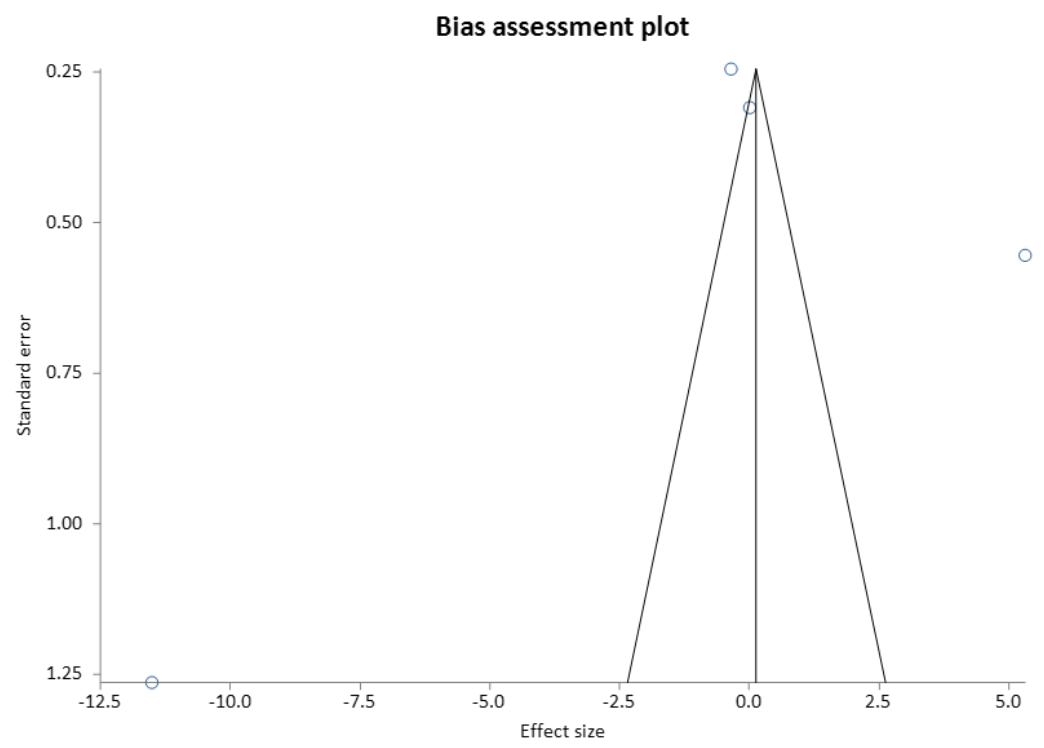

Figure No. 8

Publication bias indicators for the outcome of " $\Delta \mathrm{TG}$ " in the studies considering pistachio comparing to placebo therapy in metabolic syndrome patients and healthy people 
Effect of pistachio compared to placebo on total cholesterol (TC) in patients with metabolic syndrome The summary for standardized effect size on mean differences of total cholesterol (TC) " $\Delta \mathrm{TC}$ " in patients with metabolic syndrome from 3 trials for pistachio therapy compared to placebo (Kocyigit et al., 2006; Wang et al., 2012; Gulati et al., 2014; Kasliwal et al., 2015) was -0.26 with $95 \% \mathrm{CI}=-0.57$ to 0.04 ( $\phi=0.09$, Figure No. 9). The Cochrane Q test for heterogeneity indicated that the studies are heterogeneous $(\mathrm{P}=0.4)$ and could be combined, but because of few included studies the random effects for individual and summary of effect size for standardized mean was applied. For evaluation of publication bias Egger regression of normalized effect vs. precision for all included studies for " $\Delta$ TC" in patients with metabolic syndrome among pistachio vs. placebo therapy could not be calculated because of too few strata.

Effect size meta-analysis plot [random effects]

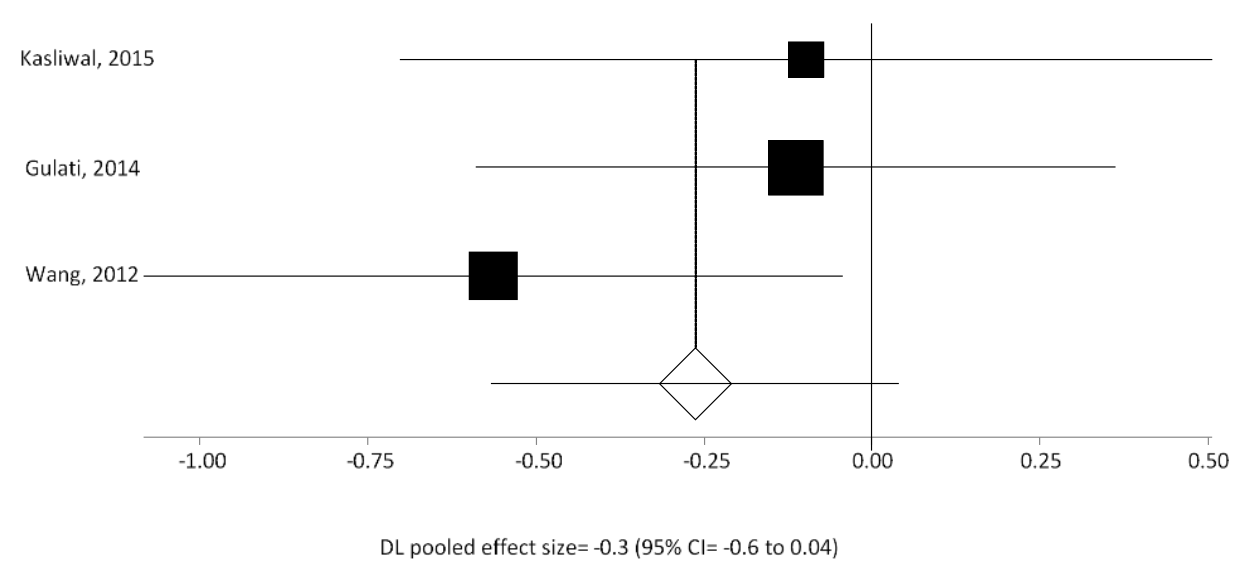

Figure No. 9

Individual and pooled effect size for the outcome of " $\Delta \mathrm{TC}$ " in the studies considering pistachio comparing to placebo therapy in metabolic syndrome patients

Effect size meta-analysis plot [random effects]

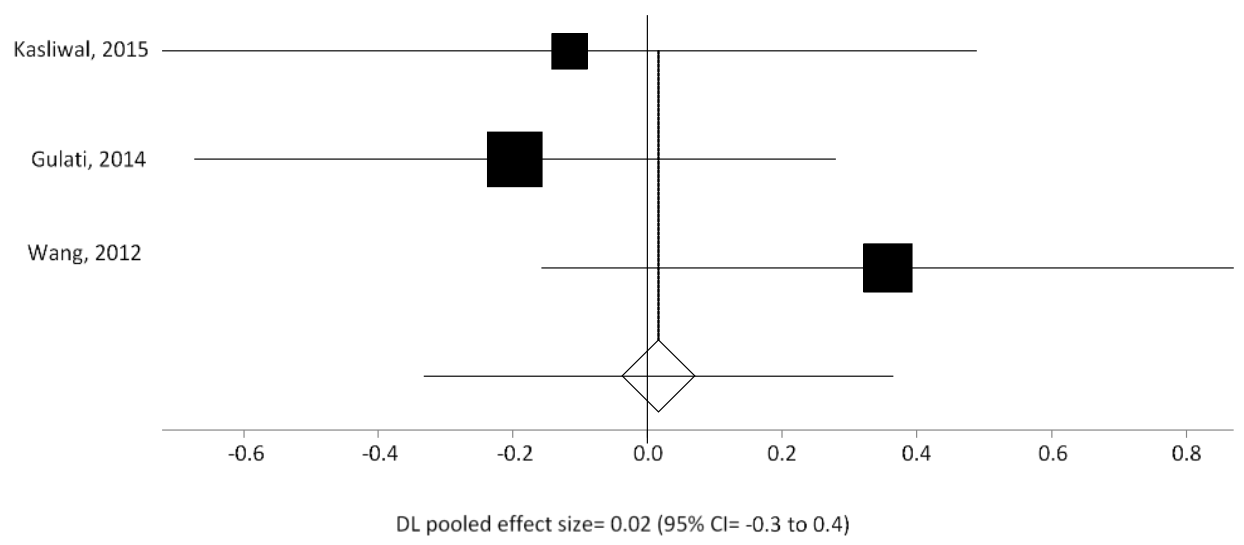

Figure No. 10

Individual and pooled effect size for the outcome of " $\triangle \mathrm{LDL}$ " in the studies considering pistachio comparing to placebo therapy in metabolic syndrome patients

Effect of pistachio compared to placebo on total LDL in patients with metabolic syndrome

The summary for standardized effect size on mean differences of LDL " $\Delta \mathrm{LDL}$ " in patients with metabolic syndrome and healthy people from 3 trials for pistachio therapy compared to placebo (Wang et al., 2012; Gulati et al., 2014; Kasliwal et al., 2015) was 0.02 with $95 \% \mathrm{CI}=-0.33$ to 0.37 ( $p=0.9$, Figure No. 10). The Cochrane $\mathrm{Q}$ test for heterogeneity indicated that the studies are heterogeneous $(p=0.3)$ and could be combined, but because of few included studies the random effects for individual and summary of effect size for standardized mean was applied. For evaluation 
of publication bias, Egger regression of normalized effect vs. precision for all included studies for " $\Delta L D L$ " in patients with metabolic syndrome among pistachio vs. placebo therapy could not be calculated because of too few strata.

Effect of pistachio in comparison to placebo therapy in total HDL in patients with metabolic syndrome The summary for standardized effect size on mean differences of HDL " $\Delta H D L$ " in patients with metabolic syndrome from 2 trials for pistachio therapy compared to placebo (Wang et al., 2012; Gulati et al., 2014) was 0.3 with 95\% CI $=-0.07$ to 0.6 ( $p=0.1$, Figure No. 11). The Cochrane Q test for heterogeneity indicated that the studies are heterogeneous $(p=0.6)$ and could be combined, but because of few included studies the random effects for individual and summary of effect size for standardized mean was applied. For evaluation of publication bias Egger regression of normalized effect vs. precision for all included studies for " $\Delta \mathrm{HDL}$ " in patients with metabolic syndrome among pistachio vs. placebo therapy could not be calculated because of too few strata.

\section{Effect size meta-analysis plot [random effects]}

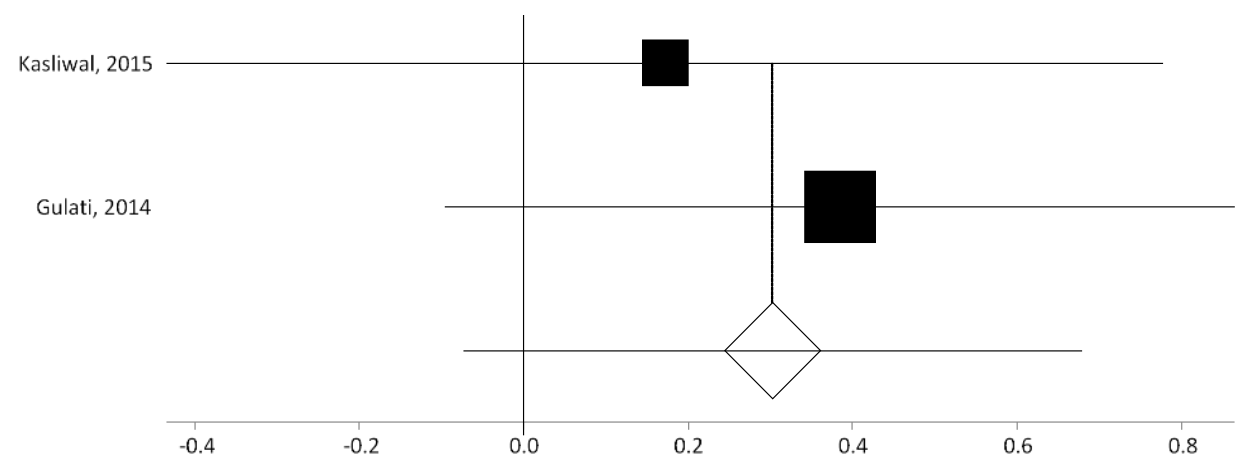

DL pooled effect size $=0.3(95 \% \mathrm{Cl}=-0.07$ to 0.7$)$

Figure No. 11

Individual and pooled effect size for the outcome of " $\Delta H D L$ " in the studies considering pistachio comparing to placebo therapy in metabolic syndrome patients

\section{Effect of pistachio compared to placebo on total TG in patients with metabolic syndrome}

The summary for standardized effect size on mean differences of TG " $\Delta \mathrm{TG}$ " in patients with metabolic syndrome from 4 trials for pistachio therapy compared to placebo (Kocyigit et al., 2006; Wang et al., 2012; Gulati et al., 2014; Kasliwal et al., 2015) was 1.6 with 95\% CI= -0.98 to 4.18 ( $p=0.2$, Figure No. 12). The Cochrane Q test for heterogeneity indicated that the studies are heterogeneous $(p<0.0001)$ and could not be combined, thus the random effects for individual and summary of effect size for standardized mean was applied. For evaluation of publication bias Egger regression of normalized effect vs. precision for all included studies for " $\Delta \mathrm{TG}$ " in patients with metabolic syndrome among pistachio vs. placebo therapy could not be calculated because of too few strata.

\section{DISCUSSION}

The aim of this systematic review and meta-analysis is to determine the effects of Pistachio on plasma lipid concentration. The present study provides the most reliable evidence from randomized clinical trials exploring the effect of pistachio on blood lipids in 213 subjects. Two studies have been carried out in India and two other studies were performed in China and Turkey. All studies have been conducted on adults whose average age exceeds thirty years. Two trials were performed for three months, one for 6 months and one for three weeks. In healthy people, pistachio has been added to their regular diet, but in patients with metabolic syndrome, a standard diet with or without pistachio was evaluated. The present meta-analysis shows remarkable effects of pistachio on lowering total cholesterol and enhancing high-density lipoprotein cholesterol (HDL). However, no significant effect was observed for lowering LDL and TG. Animal studies about pistachio effect on lipoproteins are rare. In one animal study, Aksoy and coworkers administered Pistachio to rats as $20 \%$ of caloric intake for 10 weeks. Significant increase in HDL was observed in pistachio treated rats but triglyceride and LDL cholesterol were not changed. Increasing the dose up to $40 \%$ of caloric intake didn't show considerable alteration that can be associated with more calorie intake or increasing amount 
of saturated and polyunsaturated fatty acids (Aksoy et al., 2007).

\section{Effect size meta-analysis plot [random effects]}

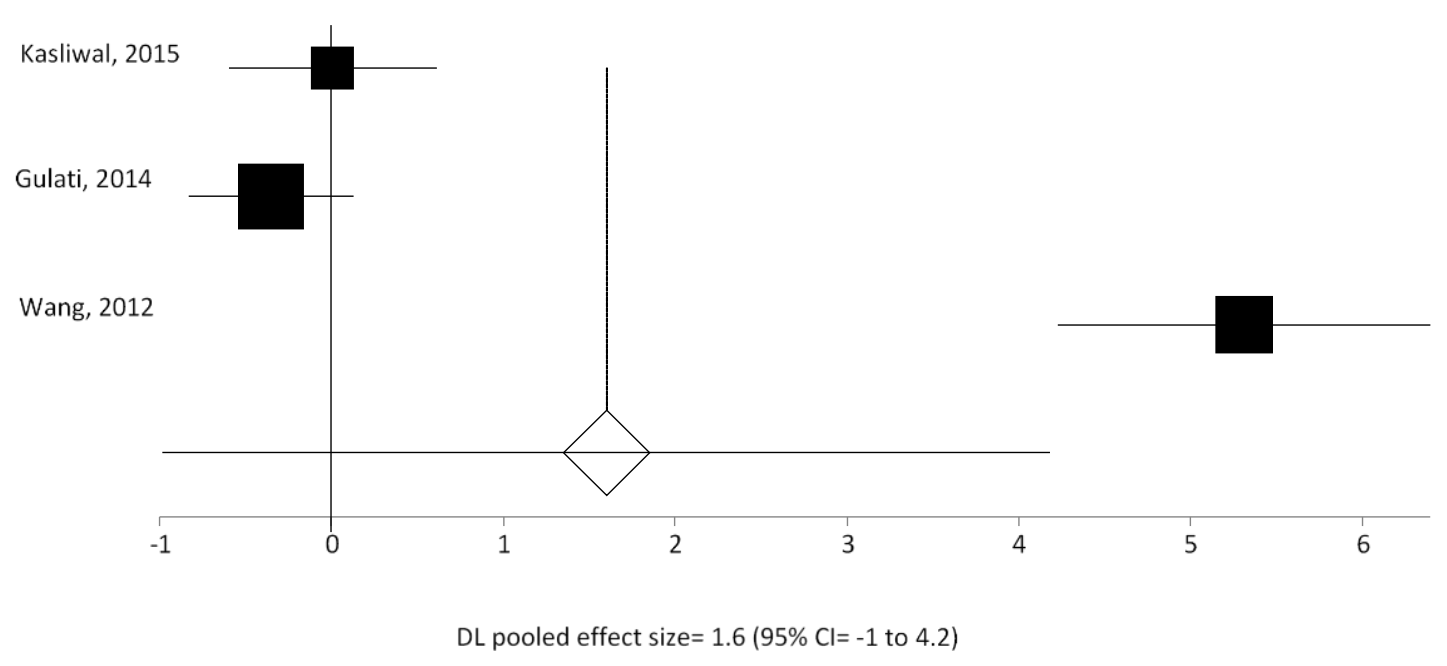

Figure No. 12

Individual and pooled effect size for the outcome of " $\Delta \mathrm{TG"} \mathrm{in} \mathrm{the} \mathrm{studies} \mathrm{considering} \mathrm{pistachio} \mathrm{comparing} \mathrm{to}$ placebo therapy in metabolic syndrome patients

There are various studies about pistachio phytochemicals and their potential efficacy for reducing blood lipids. Pistachio seed oil content is about 50-60\%. Oleic acid (C18:1) is the main monounsaturated fatty acid and linoleic acid (C18:2) is the main polyunsaturated fatty acid of pistachio oil (Bozorgi et al., 2013; Bulló et al., 2015). Different mechanisms like up-regulation of the LDL receptor and enhancement of CYP7 activity have been determined for the ability of unsaturated fatty acids for lowering LDL and increasing HDL (Fernandez \& West, 2005). The main phytosterols identified in pistachio oil include $\beta$-sitosterol, campesterol, $\Delta 5$-avenasterol, stigmasterol, brassicasterol and cholesterol (Bozorgi et al., 2013). Lipid lowering property of phytosterols is mainly related to their similarity in structure with cholesterol, which allows them to compete with cholesterol for binding to micelles in intestine and resulted in reduction of cholesterol absorption. In addition, easier hydrolysis of phytosterols lead to the reduced solubility of cholesterol in missiles and more cholesterol fecal excretion (Gupta et al., 2011). Pistachio contains phenolic compounds like gallic acid, catechin, epicatechin, resveratrol, naringenin, quercetin and luteolin. The cholesterol lowering effects of gallic acid, catechin, and epicatechin have been confirmed. These compounds delayed cholesterol absorption via inhibition of pancreatic cholesterol esterase, bile acids binding and less solubilization of cholesterol in micelles (Ngamukote et al., 2011). Likewise, resveratrol has demonstrated cholesterol-lowering activity through different mechanisms such as increasing the synthesis and efflux of bile acids, reducing cholesterol synthesis and increasing cholesterol efflux (Shao et al., 2016). In addition, pistachio contains a considerable amount of fiber. Eating a handful of pistachio nuts provides approximately 10\% of recommended daily fiber intake for healthy adults (Kasliwal et al., 2015). Some mechanisms are determined for cholesterol lowering property of fiber like inhibition of hepatic fatty acid synthesis, binding to cholesterol or bile acids during micelles formation and improvement of intestinal motility (Brown et al., 1999). The present meta-analysis showed no remarkable impact of pistachio on TG and LDL. As noted earlier, pistachio phytosterols can reduce blood lipids but treatment period enhancement or increasing the dose can be resulted in rising levels of saturated and polyunsaturated fatty acids. In case of pistachio phenolic constituents, some parameters like storage, condition and processing procedure can affect the amount and quality of these compounds (Serrano et al., 2009). So these cases may be involved in negative result of this study. The present study has some limitations; the most important of them is few numbers of high quality studies found and a small number of patients included. Moreover, included studies were heterogeneous in terms of characteristics of subjects, pistachio dose, and duration of treatment.

\section{CONCLUSION}

This meta-analysis showed a considerable effect of pistachio on reducing total cholesterol and increasing high-density lipoprotein cholesterol (HDL). However, no significant effect was observed for lowering LDL and TG. Further clinical 
trials are needed to confirm whether pistachio consumption for a certain period of time can significantly influence blood lipids.

\section{REFERENCES}

Aksoy N, Aksoy M, Bagci C, Gergerlioglu HS, Celik H, Herken E, Yaman A, Tarakcioglu M, Soydinc S, Sari I, Davutoglu V. 2007. Pistachio intake increases high density lipoprotein levels and inhibits low-density lipoprotein oxidation in rats. Tohoku J Exp Med 212: 43-48. https://doi.org/10.1620/tjem.212.43

Bahramsoltani R, Ebrahimi F, Farzaei MH, Baratpourmoghaddam A, Borkani PA, Rostamiasrabadi P, Amirabadi AHR, Rahimi R. 2017. Dietary polyphenols for atherosclerosis: a comprehensive review and future perspectives. Crit Rev Food Sci Nutr 1-19. https://doi.org/10.1080/10408398.2017.1360244

Bozorgi M, Memariani Z, Mobli M, Surmaghi MHS, Shams-Ardekani MR, Rahimi R. 2013. Five Pistacia species (P. vera, P. atlantica, P. terebinthus, P. kbinjuk, and P. lentiscus): a review of their traditional uses, phytochemistry, and pharmacology. Sci World J 2013: 219815. https://doi.org/10.1155/2013/219815

Brown L, Rosner B, Willett WW, Sacks FM. 1999. Cholesterol-lowering effects of dietary fiber: a meta-analysis. Am J Clin Nutr 69: 30-42. https://doi.org/10.1093/ajen/69.1.30

Bulló M, Juanola-Falgarona M, Hernández-Alonso P, Salas-Salvadó J. 2015. Nutrition attributes and health effects of pistachio nuts. Br J Nutr 113: S79-S93. https://doi.org/10.1017/S0007114514003250

Del Gobbo LC, Falk MC, Feldman R, Lewis K, Mozaffarian D. 2015. Effects of tree nuts on blood lipids, apolipoproteins, and blood pressure: systematic review, meta-analysis, and dose-response of 61 controlled intervention trials-3. Am J Clin Nutr 102: 1347-1356. https://doi.org/10.3945/ajcn.115.110965

DerMarderosian A, Beutler JA. 2002. The review of natural products: the most complete source of natural product information. Facts and Comparisons. Wolters Kluwer Health. St Louis, USA

Dreher ML. 2012. Pistachio nuts: composition and potential health benefits. Nutr Rev 70: 234-240. https://doi.org/10.1111/j.1753-4887.2011.00467.x

Expert Panel on Detection, Evaluation, and Treatment of High Blood Cholesterol in Adults. 2001. Executive summary of the Third Report of the National Cholesterol Education Program (NCEP) expert panel on detection, evaluation, and treatment of high blood cholesterol in adults (Adult Treatment Panel III). JAMA 285: 2486. https://doi.org/10.1001/jama.285.19.2486

Fernandez ML, West KL. 2005. Mechanisms by which dietary fatty acids modulate plasma Lipids1. J Nutr 135: 20752078. https://doi.org/10.1093/jn/135.9.2075

Gebauer SK, West SG, Kay CD, Alaupovic P, Bagshaw D, Kris-Etherton PMK. 2008. Effects of pistachios on cardiovascular disease risk factors and potential mechanisms of action: a dose-response study.Am J Clin Nutr 88: 651-659. https://doi.org/10.1093/ajcn/88.3.651

Gotto AM, Toth PP. 2016. Comprehensive management of high risk cardiovascular patients. CRC Press, Boca Raton, USA.

Gulati S, Misra A, Pandey RM, Bhatt SP, Saluja S. 2014. Effects of pistachio nuts on body composition, metabolic, inflammatory and oxidative stress parameters in Asian Indians with metabolic syndrome: a 24-wk, randomized control trial. Nutrition 30: 192-197. https://doi.org/10.1016/j.nut.2013.08.005

Gupta A, Savopoulos C, Ahuja J, Hatzitolios A. 2011. Role of phytosterols in lipid-lowering: current perspectives. QJM 104: 301-308. https://doi.org/10.1093/qjmed/hcr007

Hernández-Alonso P, Salas-Salvadó J, Baldrich-Mora M, Juanola-Falgarona M, Bulló M. 2014. Beneficial effect of pistachio consumption on glucose metabolism, insulin resistance, inflammation, and related metabolic risk markers: a randomized clinical trial. Diabetes care 37: 3098-3105. https://doi.org/10.2337/dc14-1431

Jadad AR. 1998. Randomised controlled trials: a user's guide. Health Technol Assess 2: 214.

Kasliwal RR, Bansal M, Mehrotra R, Yeptho KP, Trehan N. 2015. Effect of pistachio nut consumption on endothelial function and arterial stiffness. Nutrition 31: 678-685. https://doi.org/10.1016/j.nut.2014.10.019

Kocyigit A, Koylu A, Keles H. 2006. Effects of pistachio nuts consumption on plasma lipid profile and oxidative status in healthy volunteers. Nutr Metab Cardiovasc Dis 16: 202-209.

Koene RJ, Prizment AE, Blaes A, Konety SH. 2016. Shared risk factors in cardiovascular disease and cancer. Circulation 133: 1104-1114. https://doi.org/10.1161/CIRCULATIONAHA.115.020406

Li Z, Song R, Nguyen C, Zerlin A. Karp H, Naowamondhol K, Thames G, Gao K, Li L, Tseng CH, Henning SM, Heber D. 2010. Pistachio nuts reduce triglycerides and body weight by comparison to refined carbohydrate snack in obese subjects on a 12-week weight loss program. J Am Coll Nutr 29: 198-203. 
https://doi.org/10.1080/07315724.2010.10719834

Mathers CD, Loncar D. 2006. Projections of global mortality and burden of disease from 2002 to 2030. PLoS Med 3: e442. https://doi.org/10.1371/journal.pmed.0030442

Ngamukote S, Mäkynen K, Thilawech T, Adisakwattana S. 2011. Cholesterol-lowering activity of the major polyphenols in grape seed. Molecules 16: 5054-5061. https://doi.org/10.3390/molecules16065054

Pan L, Yang Z, Wu Y, Yin RX, Liao Y, Wang J, Gao B, Zhang L. 2016. The prevalence, awareness, treatment and control of dyslipidemia among adults in China. Atherosclerosis 248: 2-9. https://doi.org/10.1016/j.atherosclerosis.2016.02.006

Sauder KA, McCrea CE, Ulbrecht JS, Kris-Etherton PM, West SG. 2015. Effects of pistachios on the lipid/lipoprotein profile, glycemic control, inflammation, and endothelial function in type 2 diabetes: A randomized trial. Metabolism 64: 1521-1529. https://doi.org/10.1016/j.metabol.2015.07.021

Serrano J, Puupponen-Pimiä R, Dauer A, Aura AM, Saura-Calixto F. 2009. Tannins: current knowledge of food sources, intake, bioavailability and biological effects. Mol Nutr Food Res 53: S310-S329. https://doi.org/10.1002/mnfr.200900039

Shao D, Wang Y, Huang Q, Shi J, Yang H, Pan Z, Jin M, Zhao H, Xu X. 2016. Cholesterol-lowering effects and mechanisms in view of bile acid pathway of resveratrol and resveratrol glucuronides. J Food Sci 81: H2841H2848. https://doi.org/10.1111/1750-3841.13528

Sheridan MJ, Cooper JN, Erario M, Cheifetz CE. 2007. Pistachio nut consumption and serum lipid levels. J Am Coll Nutr 26: 141-148. https://doi.org/10.1080/07315724.2007.10719595

Wang X, Li Z, Liu Y, Lv X, Yang W. 2012. Effects of pistachios on body weight in Chinese subjects with metabolic syndrome. Nutr J 11: 20. https://doi.org/10.1186/1475-2891-11-20

Yusuf S, Hawken S, Ônpuu S, Dans T, Avezum A, Lanas F, McQueen M, Budaj A, Pais P, Varigos J, Lisheng L. 2004. Effect of potentially modifiable risk factors associated with myocardial infarction in 52 countries (the INTERHEART study): case-control study. Lancet 364: 937-952.

https://doi.org/10.1016/S0140-6736(04)17018-9 